\title{
Helminth parasites and reservoir status of captive wild ruminants in the semi-arid region of north-eastern Nigeria
}

\author{
Umar I Ibrahim ${ }^{1 *}$, Albert W Mbaya ${ }^{2}$, Yaqub A Geidam ${ }^{1}$ Halima I Gambo ${ }^{3}$, Kyari A Sanda ${ }^{4}$, Okoro L Kelechi ${ }^{1}$ \\ 1. Department of Veterinary Medicine, Faculty of Veterinary Medicine, University of Maiduguri, Maiduguri, \\ Nigeria 2. Department of Veterinary Microbiology and Parasitology, Faculty of Veterinary Medicine, \\ University of Maiduguri, Nigeria 3. Department of Veterinary Pathology, Faculty of Veterinary Medicine, \\ University of Maiduguri, Nigeria 4. Department of Veterinary Physiology, Pharmacology and Biochemistry, \\ Faculty of Veterinary Medicine University of Maiduguri, Nigeria.
}

Corresponding author: Umar I. Ibrahim, E-mail: umarisaibrahim@yahoo.com, Phone: +234 8036422704

Received: 07-03-2012, Accepted: 28-03-2012, Published Online: 22-06-2012

doi: $10.5455 /$ vetworld.2012.530-534

\begin{abstract}
Aim: To determine the various helminth parasites and associated helminth reservoir status of captive wild ruminants in the semi-arid region of north-eastern, Nigeria.

Materials and Methods: Faecal samples were examined for nematode ova by the simple floatation technique using saturated sodium chloride solution as floatation medium. Trematode eggs were examined by the sedementation technique. The modified McMaster technique was used to determine the intensity of helminth infections among the various species of wild ruminants examined, while larval isolation and identification using the modified Baerman's technique was used to determine the various species of parasites encountered.

Results: Out of the 36 samples examined, a high parasite count due to Strongyle infection without the manifestation of overt clinical signs was observed among the captive wild ruminants. The egg counts ranged from $500 \pm 10.0$ among the Grimm's duicker (Sylvicaprea grimmia) to 5,350 \pm 51.70 among the Senegal hartebeest (Damaliscus korrigum). The helminth larvae recovered which were common to all the species of wild ruminants were those of Haemonchus contortus, Trichostrogylus axei and Strongyloides papillosus, Demographic data such as age, sex and species of wild animals showed no significant ( $p>0.05)$ variation on the prevalence of the helminth infections.

Conclusion: The results of this study suggests that the captive wild ruminants in the semi-arid region of north-eastern, Nigeria, were reservoirs of various helminth parasites of medical and veterinary importance. It was therefore, recommended that improved sanitary conditions in animal enclosures, regular and strategic anthelmintic medications may on one hand protect the spread of infection to attendants and visitors to the park. On the other hand it will enhance the in-situ conservation of the rare and endangered species of wild ruminants in the area.

Key words: Captive wild ruminants, Helminth parasites, Reservoir status, Nigeria.
\end{abstract}

To cite this article: Ibrahim UI, Mbaya AW, Geidam YA, Gambo HI, Sanda KA, Kelechi OL (2012) Helminth parasites and reservoir status of captive wild ruminants in the semi-arid region of north-eastern Nigeria, Vet World, 5(9): 530-534, doi: 10.5455/vetworld.2012.530-534

\section{I ntroduction}

Many cases of resistance to helminth infections in wildlife often breakdown when they are translocated from their natural habitat to the unnatural conditions as obtained in captivity [1]. Thus, the free ranging reindeer, in Northern England hardly harboured Strongyle infections because of the sparseness of the molluscan intermediate hosts in those areas, yet when they were relocated to zoos they showed high levels of strongylosis [2]. Most of the animals in Nigerian zoos were once free living before they were subjected to captivity. In order to ascertain the health status of wild and captive animals at Ibadan in South-Western Nigeria, their bacterial and parasitic diseases were extensively studied and reported [3-7]. Similar studies have also been conducted [8,9] at the Kainji Lake National Park in central Nigeria, and at Maiduguri zoo $[10,11]$.

Helminth parasites are significant pathogens of wildlife and are responsible for unthriftness, decrease in fecundity rates and sometimes death [12]. Overcrowding, dampness and unsanitary conditions are predisposing factors for the proliferation of helminthic infections [13]. Such adverse conditions occur frequently under captivity than under free-living conditions [14, 15]. In as much as mixed infections of parasitic infections have been reported in several domestic animal species [16, 17],

single infections of mites [1] and mixed infections of nematodes $[11,18]$ have also been reported in a 
Helminth parasites and reservoir status of captive wild ruminants in the semi-arid region of north-eastern Nigeria

Table-1. Helminth parasites of different species of captive wild ruminants examined at Sanda Kyarimi Park, Maiduguri, Nigeria

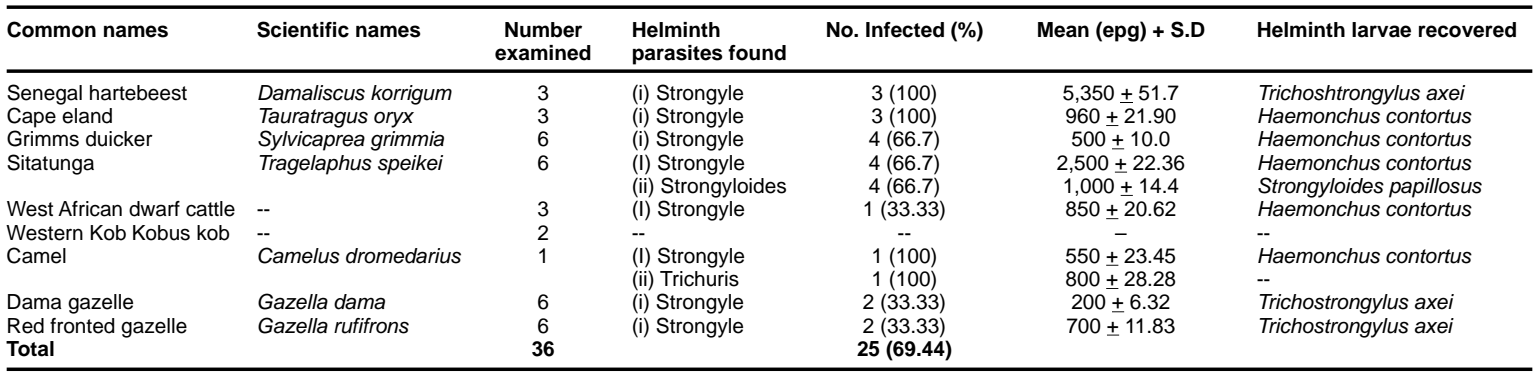

variety of wild animals kept in captivity for long periods. This study was therefore, conducted at the Sanda Kyarimi Park in the semi-arid region of northeastern, Nigeria in order to establish the helminth reservoir status of the captive wild ruminants.

\section{Materials and Methods}

The study area: The Sanda Kyarimi Park where this study was conducted is located in Maiduguri, the capital and largest urban centre in Borno State, Nigeria. The state lies between the Sudan savannah and Sahel vegetation zones characterised by a short rainy season of 3 - 4 months (June - September). The rainy season precedes a prolonged dry season of more than 8 months duration, when environmental conditions are not favourable for the development and survival of pre-parasitic stages of parasitic helminths $[10,11,19]$.

Collection of faecal samples: Faecal samples were collected as they were freshly dropped from 36 captive wild ruminants. Each sample was labelled and accompanied with demographic data such as place of collection, age and sex of each animal. A total of 100 samples were collected during several visits to the park.

Examination of faecal samples: Faecal samples were examined for nematode ova by the simple floatation technique using saturated sodium chloride solution as floatation medium [20-23] while, trematode ova were examined using sedimentation technique [24]. The morphological identification of helminth ova was done according to standard criteria [17,21].

Estimation of egg count per gram of faeces / larval isolation and identification: Quantification of helminth eggs was determined using modified McMaster technique with saturated sodium chloride solution as floatation medium [24] while larval isolation and identification to determine the species of helminths encountered was carried out using the modified Baerman`s technique [17, 21].
Statistical analysis of data: Data obtained were either summarized as means \pm standard deviation or percentages and the difference between means were determined using the ' $\mathrm{t}$ '- test at the $5 \%$ level of significance [25].

\section{Results}

The helminth parasites of wild ruminants examined at Sanda Kyarimi Park Maiduguri are presented in Table-1. A total of 36 captive wild ruminants, representing nine (9) different species such as camel (Camelus dromedarius), western kobs (Kobus kob), Senegal hartebeests (Damaliscus korrigum), sitatungas (Tragelaphus speikei), cape elands (Tauratragus oryx), Grimm's duikers (Sylvicaprea grimmia), West African dwarf cattle, red fronted gazelles (Gazella rufifrons) and dama gazelles (Gazella dama) were examined. Worm burdens were expressed as mean egg counts per gram of faeces (epg) among the different species of captive wild ruminants examined. The various parasites encountered were expressed in percentages of which $3(100 \%)$ of the Senegal hartebeest examined tested positive for Strongyle eggs with a mean epg of 5,350 \pm 51 . the helminth larvae recovered in this case was Trichostrongylus axei. Out of the three cape elands (Tauratragus oryx) examined, all of them (100\%) tested positive for Strongyle egg with a mean epg of $960 \pm 21.90$, while helminth larvae recovered were those of Haemonchus contortus. Similarly, out of the six Grimm's duikers (Syvicapra grimmia) examined, 4 $(66.7 \%)$ tested positive for Strongyle eggs with a mean (epg) of $500 \pm 10.0$ with Haemonchus contortus larvae recovered. Out of the three West African dwarf cattle examined, 1(33.33\%) tested positive for Strongyle eggs with a mean (epg) of $850 \pm 20.62$, with Haemonchus contortus larvae recovered. Out of the six sitatungas (Tragelaphus speikei) examined, 4 $(66.7 \%)$ tested positive for Strongyle and the helminth larvae recovered were those of Haemonchus contortus 
Helminth parasites and reservoir status of captive wild ruminants in the semi-arid region of north-eastern Nigeria

Table-2. Age distribution of helminth parasites of captive wild ruminants examined at Sanda Kyarimi Park, Maiduguri, Nigeria

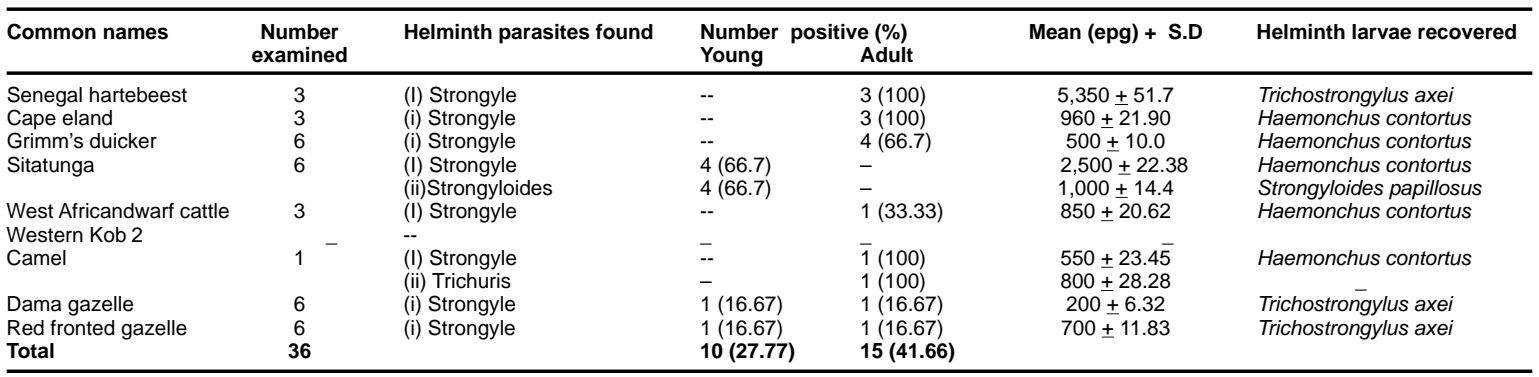

Table-3. Sex distribution of helminth parasites of captive wild ruminants examined at Sanda Kyarimi Park, Maiduguri, Nigeria

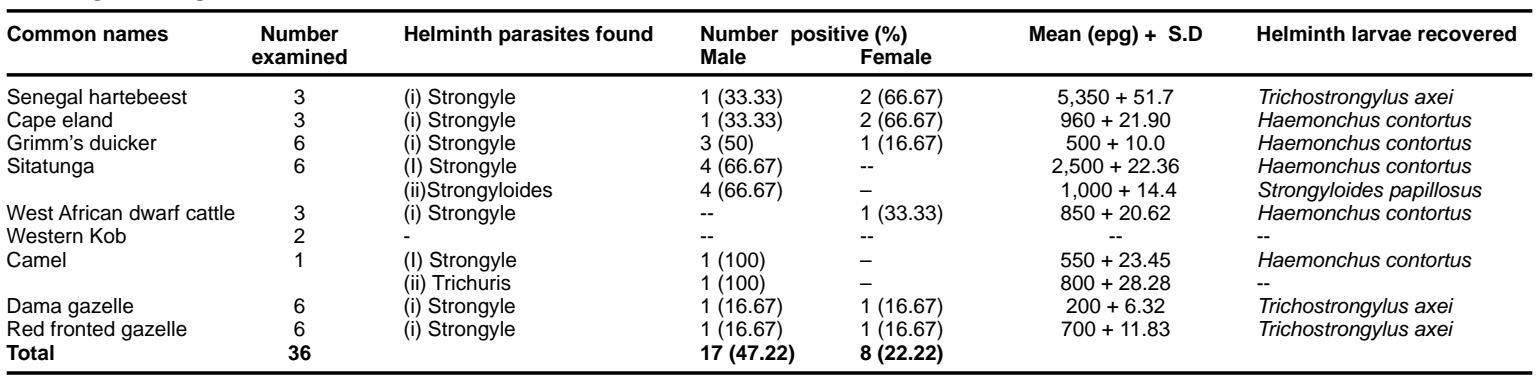

and Strongyloides papillosus with a mean epg of 2,500 \pm 22.36 and $1,100 \pm 14.4$ respectively while no parasite larvae were recovered from the two western kobs (Kobus kob) examined.

The only camel (Camelus dromedarus) examined tested positive for both Strongyle and Trichuris specie with mean epg of $550 \pm 23.45$ and $800 \pm 28.28$ respectively, with Haemonchus contortus larvae recovered. Two (53.33\%) out of the six dama gazelles (Gazella dama) examined during this study tested positive for Strongyle with a low (epg) of $22 \pm 6.32$ while helminth larvae recovered were those of Trichostrongylus axei.

A total of six red fronted gazelle (Gazella rufifrons) were examined in this study, where 2 $(33.33 \%)$ tested positive for Strongyle egg with a mean epg of $700 \pm 11.83$ while helminth larvae recovered were those of Trichostrongylus axei.

The age distribution of the helminth parasites of captive wild ruminants examined at the Sanda Kyarimi Park, Maiduguri, Nigeria is presented in Table-2. All three Senegal hartebeest (Damaliscus korrigum) examined were adults and all tested positive for Strongyle with mean epg of 5, 350 \pm 51.70 with Trichostrongylus axei larvae recovered. Three adult cape elands (Tauratragus oryx) were examined and all 3(100\%) were positive for Strongyle ova with a mean epg of $960 \pm 21.90$ while $H$. contortus larvae were recovered. Out of the six sitatunga (Tragelaphus speikei) examined, 4(66.7\%) were young and infected with Strongyle with a mean epg of 2,500 \pm 22.38 , while helminth larvae recovered were those of Haemonchus contortus. In addition, $4(66.7 \%)$ tested positive for Strongyloides with a mean epg of 1,000 \pm 14.14 with the larvae of Strongyloides papillosus recovered. Out of the $3(100 \%)$ West African dwarf cattle examined, $1(33.33 \%)$, adult tested positive for Strongyle eggs with mean epg of $850 \pm 20.62$ while the larvae recovered were those of $H$. contortus. The only adult camel (Camelus dromedarus) examined, 1 (100\%) was positive for both Strongyle and Trichuris with an epg of $550 \pm 23.45$ and $800 \pm 28.28$ respectively with Haemonchus contortus larvae recovered. Out of the six-dama gazelles examined, five were adults and one young. One adult dama gazelle and the only young tested positive for Strongyle eggs with a mean epg of $200 \pm 6.22$ in both cases, with Trichostrongylus axei larvae recovered. Six red fronted gazelles comprising of 5 adults and one young were examined during this study.

Only $1(16.67 \%)$ adult and one $1(16.67 \%)$ young tested positive for Strongyle with a mean epg \pm of 700 \pm 11.83 for both animals while the helminth larvae recovered were those of Trichostrongylus axei.

The distribution of helminth parasites of captive wild ruminants in Sanda Kyarimi Park, Maiduguri 
according to sex and their associated worm burden is presented in Table- 3 .

$1(33.33 \%)$ out of the 3 Senegal hartebeests (Damaliscus korrigum) examined during this study was a male with 2 females. Both sexes tested positive for Strongyle with a mean epg of 5,350 \pm 51.70 , while the helminth larvae recovered were those of Trichostrongylus axei. Only 1(33.33\%) of the cape eland (Tauratragus oryx) was a male, which tested positive for Strongyle eggs. The other two were females, which tested positive for Strongyle eggs with a mean epg of $960+21.90$, and the helminth larvae recovered were those of Haemonchus contortus. Out of the six Grimm's duiker (Sylvicaprea grimmia) examined during the study, $3(50 \%)$ were males while $3(50 \%)$ were females. One $(16.67 \%)$ out of the females tested positive for Strongyles while all the 3 males tested positive for Strongyle with a mean epg of $500 \pm 10.00$, with Haemonchus contortus larvae recovered. Out of the 6 sitatungas (Tragelaphus speikei) examined $4(66.7 \%)$ were males which tested positive for both Strongyles and Strongyloides. Mean (epg) for Strongyle was 2,500 +22.36 and 1,000 \pm 14.14 for Strongyloides while Haemonchus contortus and Trichostrongylus axei larvae were recovered. Two out of the six sitatungas (Tragelaphus speikei) in the park were females and were negative for helminth eggs. One $(33.33 \%)$ out of the three West African dwarf cattle examined during this study was a female which was positive for Strongyle eggs with a mean epg of $850 \pm 20.62$ while the helminth larvae recovered were those of Haemonchus contortus. The remaining two were males, which were positive for helminth ova. The only camel (Camelus dromedarus) present in the park during the study was a male in which Trichuris and Strongyle were encountered with a mean epg of $550 \pm 23.45$ and $800 \pm 28.28$ due to Strongyles and Trichuris specie respectively with $H$. contortus larvae recovered. Out of the six dama, gazelles examined, two, (One male and one female) were positive for Strongyles, with a mean epg of $200 \pm 6.32$ in both cases, where Trichostrongylus axei was the helminth larvae recovered. Strongyle was equally encountered in two of the six red fronted gazelles (Gazella rufifrons) present in the park, where $1(16.67 \%)$ male and $1(16.67 \%)$ female were positive for Strongyle with a mean epg of $700 \pm 11.83$ with Trichostrongylus axei larvae encountered.

\section{Discussion}

All the parasites recovered from the various species of wild ruminants are common to domestic animals in Nigeria [10]. They have previously been reported to occur among captive wild ruminants in the same park [11]. However, the present study recorded a very high egg counts as compared to the previous study. This study, which was conducted from June to September (rainy season), probably influenced the high egg count. Most parasites tend to reach their highest biotic potential during the rainy season [15]. Secondly, the larval infectivity and acquisition has been reported by several researchers to increase tremendously during the rainy season $[1,6]$. Furthermore, the general high egg counts encountered among the wild ruminants as compared to those of an earlier study in the park $[10,11]$ showed that the deterioration of sanitary conditions in the park and irregular anthelmintic medications over the years played a vital role in the epidemiology of the infections.

The sitatunga (Tragelaphus spekei) and the Senegal hartebeest (Damaliscus korrigum) however, recorded the highest egg counts of 2,500 and 5,350 respectively due to Strongyle infection. The larvae recovered were those of Haemonchus contortus, and Trichostrongylus axei. Under normal circumstances, such high egg count often resulted into overt disease or outbreaks among domestic animals [17]. However, the absence of overt clinical signs or death in this species of wild ruminants in particular might be associated with innate resistance to helminthosis due to their reservoir status as wild animals [18]. Despite these, it has been reported that many cases of presumed resistance to helminthosis in wildlife often break down when subjected to the stress of captivity [1].

The camel (Camelus dromedarus) for the first time harboured Trichuris trichuria, a parasite of humans and primates. This strange occurrence might be associated with 'spurious' infection or likely a new host adaptation [17]. Trichuris trichuria have been reported among captive chimpanzee (Pan troglodytes) in the same park [26]. The occurrence of the same parasites in several of the groups examined agrees with previous reports $[10,11]$ where one attendant was responsible for cleaning several pens, cages and enclosures thereby acting as a vehicle of cross transmission between different animal groups.

\section{Conclusion}

The results of this study suggests that the captive wild ruminants in the semi-arid region of northeastern, Nigeria, are reservoirs of various helminth parasites of medical and veterinary importance. It was therefore, recommended that improved sanitary conditions, in animal enclosures, balanced nutrition, environmental enrichment, regular and strategic anthelmintic medications may on one hand protect the spread of infection to 
attendants and visitors to the park. On the other hand it will enhance the in-situ conservation of these rare and endangered species of wild ruminants in the area.

\section{Author's contribution}

UII, AWM and OLK implemented study design, recorded data and analysis. UII, AWM, YAG and HIG drafted the manucript. All authors revised the manuscript, read and approved the final manuscript.

\section{Acknowledgements}

The effort and support of the management and staff of Sanda Kyarimi Park, Maiduguri, Nigeria are highly appreciated.

\section{Competing interests}

Authors declares that they have no competing interest.

\section{References}

1. Dunn, A. M. (1978). Veterinary Heminthology. $2^{\text {nd }}$ edn. William Heinemann Medical Books Limited, London, pp. 120-124.

2. Jansen, J. JR. (1963). Some problems related to the parasite inter-relationships of deer and domestic animals. Trans. Congr. Int. Union Game Biol. 6, 127-131.

3. Enyinihi, U. K. (1972). Parasitic infection of animals in the University of Ibadan zoo. African Journal of Medical Sciences 3, 283-293.

4. Dipeolu, O. O. (1975). Public health aspects of parasitic infection of zoo: Agodi gardens experience. The Veterinary Surgeon 4, 40-43.

5. Falade, S. and Durojaiye O. A. (1976). Salmonella isolated from Nigerian captive animals in Ibadan. Journal of Wildlife Diseases 12, 464-468.

6. Bamidele, O. and Ogunrinade, A. F. (1980). Helminth parasites of captive animals. African Journal of Ecolology 18, 265-266.

7. Agbede, S. M. and Yesefu, A. M. (1982). Helminth parasites of wild carnivores in the zoological garden of University of Ibadan and the public health aspects. Nigerian Veterinary Journal 11, 19-22.

8. Ogunji, F.O., Akinboade, O. A. and Dipeolu, O. O. (1982). Gastro-intestinal parasites and bacterial flora of wild animals in Borgu Game Reserve in Nigeria. International Journal of Zoonoses 9, 62-64.

9. Crocket, E. C. (1983). A preliminary survey of some helminth parasites of game animals in Kainji Lake National Park: Borgu Sector. MSc. Thesis, University of Ibadan, Nigeria, pp 148-149.

10. Nwosu, C.O. (1995). Helminth parasites of captive and free-living wild animals in Borno State, Nigeria. Tropical Veterinarian 13, (1/2).

11. Mbaya, A.W. et al (2006). A comparative study of gastrointestinal parasites of captive and free-living wild animals in the semi-arid zone of northeastern Nigeria. Nigerian Journal of Experimental and
Applied Biology 7, 185-193.

12. Davies, J. W. and Anderson, R. C. (2004). Parasitic Diseases of Wildlife, Iowa State University Press, pp. 45-47.

13. Radostitis, O. M., Blood, D. C. and Gray, C. C. (1997). Veterinary Medicine. A textbook of the diseases of Cattle, Sheep, Goats, Pigs and Horses. $8^{\text {th }}$ edn. Saunders Ltd, London, pp. 671-676.

14. Young, E. (1970). The capture and care of wild animals. $1^{\text {st }}$ edition. Ralph Curtis Books, Hollywood, Florida, USA, pp. 202-203

15. Devos, V. and Lambrechts, M. C. (2003). Emerging aspects of wildlife diseases in Southern Africa. In: Proceedings of Sarcus Symposium on Nature Conservation as a Form of Land (13-17 September). Gorongosa National Park, Mozambique, pp. 97-99.

16. Soulsby, E. J. L. (1963). Clinical Diagnostic Method. In: Textbook of Veterinary Clinical Parasitology I: Helminths. Blackwell Scientific Publications, Oxford, London, pp.763-778.

17. Soulsby, E. J. L. (1982). Helminths, Arthropods and Protozoa of Domesticated Animals. $7^{\text {th }}$ edition. Bailliere Tindall, London, pp. 809-810.

18. Mbaya, A. W. and Aliyu, M. M. (2006). Mixed infections of Notoedres cati and Ancylostoma caninum among captive lions (Panthera leo) at the Sanda Kyarimi Park, Maiduguri, Nigeria. Sahel Journal of Veterinary Sciences 5, 5-8.

19. Mbaya, A.W., Nwosu, C.O. and Biu, A. A. (1999). Prevalence of Toxocara (Neoascaris) vitulorum infection in cattle in the semi-arid region of North-eastern Nigeria. Indian Veterinary Medical Journal 23, 35-37.

20. Anonymous (1977). Manual of Veterinary Parasitological Laboratory Techniques. Technical Bulletin No 18, Ministry of Agriculture, Fisheries and Food, London, pp. 129-132.

21. Sloss, M. W., Kemp, R. L. and Zajac, A. M. (1994). Veterinary Clinical Parasitology. $5^{\text {th }}$ edn. Iowa State University Press, Ames, Iowa, USA, pp. 48-219.

22. Kaufmann, J. (1996). Parasite infection of domestic animals. In: Kassai, T., Veterinary Helminthology. A diagnostic manual. Birkhauser Verlage, Basel, pp. 186-190.

23. Kassai, T. (1999). Diagnostic Helminthology. In: Veterinary Helminthology, $1^{\text {st }}$ edn. Butter. WormHeinemann, Linacre House Jordan Hill, Oxford, pp. $185-197$.

24. Hansen, J. and Perry, B. (1990). The Epidemiology, Diagnosis and Control of Gastrointestinal parasites. ILRAD, Nairobi, Kenya, pp. 121-125.

25. Maed, R. and Curnow R. N. (1983). Statistical methods in Agriculture and Experimental Biology, Chapman and Hall, London, pp. 123-126.

26. Mbaya, A. W. and Nwosu, C.O. (2006). Outbreak of clinical amoebaisis among captive chimpanzees (Pan troglodytes) at the Sanda Kyarimi Park, Maiduguri, Nigeria. Nigerian Veterinary Journal 27 (1), 68-73. 